\title{
Origins and global context of Brucella abortus in Italy
}

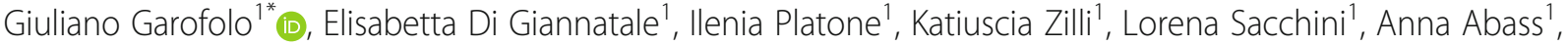 \\ Massimo Ancora', Cesare Cammà', Guido Di Donato ${ }^{1}$, Fabrizio De Massis ${ }^{1}$, Paolo Calistri ${ }^{1}$, Kevin P. Drees ${ }^{2}$ \\ and Jeffrey T. Foster ${ }^{2}$
}

\begin{abstract}
Background: Brucellosis is a common and chronic disease of cattle and other bovids that often causes reproductive disorders. Natural infection in cattle is caused by Brucella abortus and transmission typically occurs during abortions, calving, or nursing. Brucellosis is also a major zoonotic disease due to contamination of dairy products or contact with the tissues of infected animals. Brucellosis has been eradicated from most of the developed world in the last 40 years but persists in many regions - the disease remains prevalent in portions of Africa, the Middle East, Asia, and Central and South America, as well as in the Mediterranean basin. In Italy, B. abortus has persisted in southern regions in both cattle and water buffalo. Previous attempts at analyzing the phylogenetics of $B$. abortus in Italy have been challenging due to limited genetic variability and unresolved global population genetic structure of this pathogen.
\end{abstract}

Results: We conducted genome-wide phylogenetic analyses on 11 representative strains of $B$. abortus from Italy, and compared these sequences to a worldwide collection of publically available genomes. Italian isolates belong to three clades that are basal to the main and global B. abortus lineage. Using six SNP-based assays designed to identify substructure within the Italian clades, we surveyed a collection of 261 isolates and found that one clade predominates throughout endemic districts in the country, while the other two clades are more geographically restricted to portions of southern Italy.

Conclusions: Although related strains exist worldwide, B. abortus isolates from Italy are substantially different than those found in much of the rest of Europe and North America, and are more closely related to strains from the Middle East and Asia. Our assays targeting genetic substructure within Italy allowed us to identify the major lineages quickly and inexpensively, without having to generate whole genome sequences for a large isolate collection. These findings highlight the importance of genetic studies to assess the status and the history of pathogens.

\section{Background}

Although eradicated throughout much of the developed world, bovine brucellosis continues to be common in Southern Italy [1]. Brucella abortus, the etiological agent, is a Gram-negative non-motile and non-sporulating bacterium that forms coccobacilli with oxidative metabolism [2]. At the beginning of the 20th century, B. abortus was recognized by Benhard Bang as the causative agent of epizootic abortion in cattle. Only later was this disease connected to Malta Fever, a disease caused by a closely related species, B. melitensis, which humans typically

\footnotetext{
* Correspondence: g.garofolo@izs.it; garofolo.giuliano@gmail.com ${ }^{1}$ National and OIE Reference Laboratory for Brucellosis, Istituto Zooprofilattico Sperimentale dell'Abruzzo e del Molise "G. Caporale", Teramo, Italy Full list of author information is available at the end of the article
}

contract from infected sheep and goats [3]. Meyer classified these and other species in the genus Brucella [4]. In cattle, the disease presents primarily as reproductive disorders such as abortion, resulting in substantial economic losses to agriculture [5]. For example, the economic burden of bovine brucellosis in Latin America has been estimated at $\$ 600$ million annually [6]. Brucella abortus is a significant zoonotic agent, and humans are typically infected by consumption of raw dairy products, exposure to aerosolized bacteria at slaughter, or during veterinary care and animal husbandry [7].

The Italian government has conducted a country-wide eradication program for cattle brucellosis since 1994 [8]. Animal cases are currently limited to seven regions of southern Italy, with the highest prevalence of infection 
in areas of Sicily, Calabria, and Apulia [9]. This eradication program, along with strict regulations on cattle movements, has reduced the prevalence and geographic distribution of brucellosis in Italy [10]. In order to achieve the eradication of brucellosis, the identification of the sources of infection is essential, as is determining whether the same strains are circulating within a region or continuously reintroduced from other areas or countries. Additionally, determining the host species and source regions are important components of epidemiological tracking of transmission to humans.

Molecular epidemiology has been challenging in Brucella due to relatively high levels of nucleotide similarity throughout the genus [11]. Traditional molecular approaches involving biochemical testing are only able to categorize samples into broad phenotypic groups of biovars; eight different biovars have been described for B. abortus (biovars 1-7 and 9) [12]. More recent genetic analyses using variable number tandem repeat (VNTR) markers have given much higher resolution and can be highly informative in some cases [13-16], but homoplasy in VNTR markers and a lack of sampling for some regions make it challenging to place $B$. abortus into a global phylogeny [17] .

We used whole genome sequencing (WGS) to place 11 Italian B. abortus isolates onto a global context. We also identified specific single nucleotide polymorphisms (SNPs) that define the three major Italian clades in our study, and then developed clade-specific assays to genotype our Italian collection of 261 isolates. This genotyping allowed us to rapidly and inexpensively identify the lineages of $B$. abortus circulating in Southern Italy and place Italian strains in a global phylogeny. In Italy, where brucellosis remains a major public health concern, the information generated by this genotyping will also support epidemiological investigations of human infections.

\section{Results}

Whole genome comparisons generated approximately 9,000 putative SNPs that were used to construct a phylogenetic tree using maximum parsimony. Italian isolates of $B$. abortus were part of three clades that are basal to the most common worldwide lineage, which we refer to as the biovar 1, 2, 4 lineage (hereafter biovar 1/2/4); a lineage that is ubiquitous in North America and parts of Europe (Fig. 1). Isolates from western Italy and a closely related sample from France form a "West Italia" subclade defined by 83 SNPs, the top most clade in Fig. 1 containing Italian isolates in red. A broader clade that also includes isolates from Poland, Spain, and China is defined by 91 SNPs. Members of the West Italia subclade and broader clade are most closely related to the biovar $1 / 2 / 4$ lineage, which is consistent with the biochemical designation of most of these isolates as biovar 1.
The other Italian isolates are part of an even more basal and considerably more diverse group of $B$. abortus genomes. Unlike the biovar $1 / 2 / 4$ lineage, this basal group is comprised largely of isolates from biovars 3,5 , 6, 7, 9-isolates that are broadly distributed across Europe, Asia, and Africa. Substantial diversity among African isolates suggests this continent may be the region of origin of $B$. abortus as a species (JTF, unpubl. data) but additional sampling is necessary to test this hypothesis. Inconsistencies in biovar assignment compared to their placement in the phylogenetic tree suggest that biovar classification in $B$. abortus does not consistently reflect genetic relationships or that biochemical determination of biovars is unreliable.

Six of our isolates from across Italy form a "Trans Italia" subclade along with isolates from Mongolia, southern Europe, and Egypt, which are defined by 44 SNPs. The broader clade also includes an isolate from Turkey. The 169 SNPs exclusive to this clade suggests a fairly long time period separates these isolates from the common ancestor they share with genomes from Uganda and Iraq. Isolates from eastern Italy form an "East Italia" subclade, with 157 SNPs exclusive to the branch. The broader clade contains an isolate from Greece, which shares 145 exclusive SNPs with the East Italia cluster. Members of the East Italia subclade are closely related, although these three isolates came from three different regions.

We developed 13 Melt-MAMA assays to genotype a larger collection of 261 samples and to better define the population substructure of B. abortus in Southern Italy. Six of the Melt-MAMA assays produced consistent results and corresponded to two assays each for the West Italia, Trans Italia, and East Italia subclades and the broader clades to which they belong (Table 1). Our genotyping indicated that 13 Italian isolates came from the West Italia subclade, 214 isolates were part of the Trans Italia subclade, and 34 isolates were part of the East Italia subclade (Additional file 1: Table S1). We then mapped the geographic distributions of the clades to determine their phylogeographic patterns. The West Italia genotypes consisted entirely of isolates from biovar 1 detected in the three western Italian districts of Campania, Basilicata, and Calabria (Fig. 2). The East Italia group was found mostly in the eastern regions of southern Italy: Apulia, Molise and Abruzzo (Fig. 2). Finally, the Trans Italia group was distributed throughout endemic regions of Southern Italy, suggesting its ubiquity and dominance in the region (Fig. 2).

\section{Discussion}

Whole genome sequencing and comparison to a large global collection of genomes allowed us to determine the evolutionary history of $B$. abortus in Italy. Despite the strains being isolated exclusively in 2011, the use of 


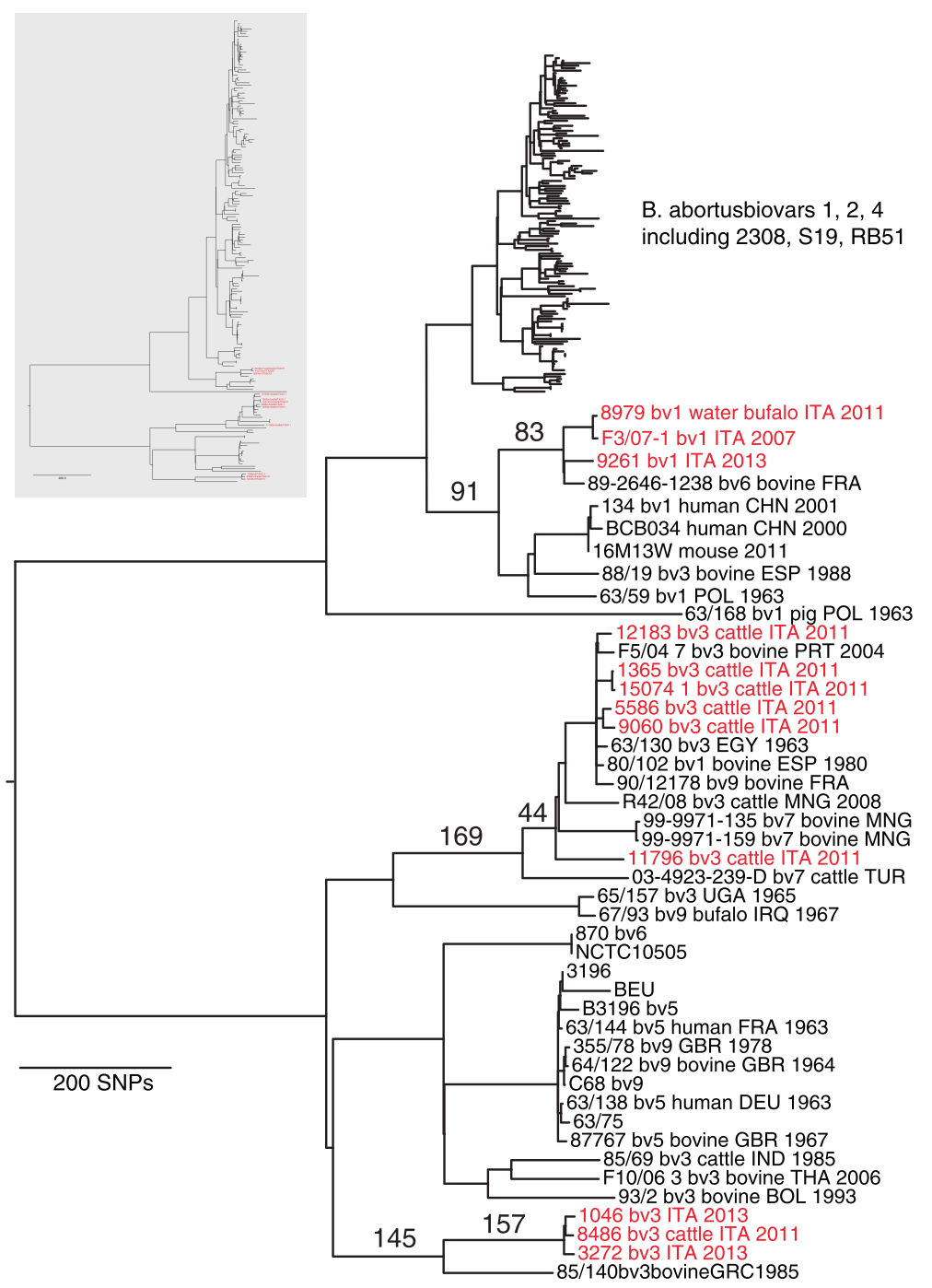

Fig. 1 Maximum parsimony tree for Brucella abortus, with genomes from Italian isolates highlighted in red. Bootstrap support values were 100 for all major branches, with only the shallowest clades having less support (data not shown). Numbered branches indicate the number of SNPs identified for the clade (left most) and subclade (right most) level groupings for the West Italia (top), Trans Italia (middle) and East Italia (bottom) subclades. Samples are identified by the strain name and where known, the biovar (bv) number, animal source, country of origin (3 letter ISO codes), and year of isolation. Top most clade containing biovars 1, 2, 4 is compressed in larger tree to fit into image, true branch lengths are represented in smaller figure in gray box

multi-locus variable number tandem repeat (VNTR) analysis (MLVA) in a previous study allowed us to select and then sequence a diverse collection of isolates from throughout endemic districts in Southern Italy [17]. Challenges with VNTRs limited our phylogenetic inference for $B$. abortus for the country. However, genomewide phylogenetics using SNPs identified that Italian strains come from three major clades, all of which are substantially different than the common biovar $1 / 2 / 4$ lineage found in much of Europe and North America. Genotyping assays supported these findings in a larger collection of 200 isolates from Italy.
We believe that the relatedness of Italian strains to lineages from other parts of Europe, Asia, and Africa suggests that $B$. abortus in Italy has a very different evolutionary history than the dominant lineage of biovar $1 / 2 / 4$ that was brought to the New World by various Europeans in infected cattle. Two or three different domestication events of wild cattle in Eurasia have occurred [18], and then cattle, with their associated diseases, were introduced by humans throughout the world [19]. Italian farms contain several European cattle breeds, but also contain several primitive cattle breeds such as Podolica, Marchigiana, Chianina, and Romagnola, which are all directly linked to 
Table 1 Characteristics of Melt-MAMA primers designed for six major branches containing Italian Brucella abortus isolates. Genome position is in the reference strain 2308, all in chromosome I

\begin{tabular}{|c|c|c|c|c|c|c|c|}
\hline Branch & $\begin{array}{l}\text { Location in B. } \\
\text { abortus } 2308\end{array}$ & $\begin{array}{l}\text { SNP } \\
\text { allele }\end{array}$ & $\begin{array}{l}\text { Melt-MAMA } \\
\text { primer }\end{array}$ & Melt-MAMA Primer sequences ( $5^{\prime}$ to $3^{\prime}$ ) & $\begin{array}{l}\text { PCR mix } \\
\text { Concentration }\end{array}$ & $\begin{array}{l}\text { Annealing } \\
\text { Temp. }\end{array}$ & $\begin{array}{l}\text { Melting } \\
\text { Temp. }\end{array}$ \\
\hline \multirow{3}{*}{$\begin{array}{l}\text { Branch } 1 \\
\text { West Italia }\end{array}$} & \multirow{3}{*}{$\begin{array}{l}951620 \\
\text { NC_007618.1 }\end{array}$} & \multirow[t]{3}{*}{$C / T$} & A & GCGACCGCATCCTCTAaTC & $0.4 \mu \mathrm{M}$ & & $80.8^{\circ} \mathrm{C}$ \\
\hline & & & $\mathrm{D}$ & cggggcggggcggggGCGACCGCATCCTCTACTT & $0.1 \mu \mathrm{M}$ & \multirow[t]{2}{*}{$56^{\circ} \mathrm{C}$} & \multirow[t]{2}{*}{$83.4^{\circ} \mathrm{C}$} \\
\hline & & & C & CATGGTAGGCAGGCTGGTT & $0.5 \mu \mathrm{M}$ & & \\
\hline Branch 2 & 1336380 & $A / G$ & A & CGAAGTTTCCCGACACCCA & $0.4 \mu \mathrm{M}$ & & $81.2^{\circ} \mathrm{C}$ \\
\hline \multirow[t]{2}{*}{ West Italia } & \multirow[t]{2}{*}{ NC_007618.1 } & & $\mathrm{D}$ & cggggcggggcggggCGAAGTTTCCCGACACCtG & $0.1 \mu \mathrm{M}$ & \multirow[t]{2}{*}{$56^{\circ} \mathrm{C}$} & \multirow[t]{2}{*}{$83.9^{\circ} \mathrm{C}$} \\
\hline & & & C & GATGAAGAAATCGATGAGCG & $0.5 \mu \mathrm{M}$ & & \\
\hline Branch 1 & 104052 & $\mathrm{G} / \mathrm{T}$ & A & TGGAGGACGAAGTCTTCGaTG & $0.25 \mu \mathrm{M}$ & & $78^{\circ} \mathrm{C}$ \\
\hline \multirow[t]{2}{*}{ East Italia } & \multirow[t]{2}{*}{ NC_007618.1 } & & $\mathrm{D}$ & cggggcggggcggggGGAGGACGAAGTCTCGCT & $0.25 \mu \mathrm{M}$ & \multirow[t]{2}{*}{$56^{\circ} \mathrm{C}$} & \multirow[t]{2}{*}{$82.9^{\circ} \mathrm{C}$} \\
\hline & & & C & ATCCTCGACAGTTGCGGC & $0.5 \mu \mathrm{M}$ & & \\
\hline Branch 2 & 360724 & $\mathrm{C} / \mathrm{A}$ & A & TACCGCGGCCCGTCTAtC & $0.25 \mu \mathrm{M}$ & & $81.6^{\circ} \mathrm{C}$ \\
\hline \multirow[t]{2}{*}{ East Italia } & \multirow[t]{2}{*}{ NC_007618.1 } & & $\mathrm{D}$ & cggggcggggcggggTACCGCGGCCCGTCTAaA & $0.25 \mu \mathrm{M}$ & \multirow[t]{2}{*}{$56^{\circ} \mathrm{C}$} & \multirow[t]{2}{*}{$83.7^{\circ} \mathrm{C}$} \\
\hline & & & $\mathrm{C}$ & AATCAAAGCGGCTTGCCTC & $0.5 \mu \mathrm{M}$ & & \\
\hline Branch 1 & 740090 & $\mathrm{~T} / \mathrm{C}$ & A & CAAAAGCGGACGGTCAgAT & $0.4 \mu \mathrm{M}$ & & $78.9^{\circ} \mathrm{C}$ \\
\hline \multirow[t]{2}{*}{ Trans Italia } & \multirow[t]{2}{*}{ NC_007618.1 } & & D & cggggcggggcggggTCAAAAGCGGACGGTCAtAC & $0.1 \mu \mathrm{M}$ & \multirow[t]{2}{*}{$56^{\circ} \mathrm{C}$} & \multirow[t]{2}{*}{$80.9^{\circ} \mathrm{C}$} \\
\hline & & & $\mathrm{C}$ & CCCTCAACCCAGACGTTCG & $0.5 \mu \mathrm{M}$ & & \\
\hline Branch 2 & 864308 & $C / T$ & A & AGGCATTACCGTTTCAGATTtC & $0.4 \mu \mathrm{M}$ & & $78.5^{\circ} \mathrm{C}$ \\
\hline \multirow[t]{2}{*}{ Trans Italia } & \multirow[t]{2}{*}{ NC_007618.1 } & & $\mathrm{D}$ & cggggcggggcggggAGGCATTACCGTTCAGATTaT & $0.1 \mu \mathrm{M}$ & \multirow[t]{2}{*}{$56^{\circ} \mathrm{C}$} & \multirow[t]{2}{*}{$81.9^{\circ} \mathrm{C}$} \\
\hline & & & C & TCTITCCCGGCTCCGAAT & $0.5 \mu \mathrm{M}$ & & \\
\hline
\end{tabular}

Melt-MAMA primer abbreviations: $A$ ancestral, $D$ derived, $C$ common

Details of primers concentration used in each reaction with proper annealing temperature is given. Melting temperatures detected for both the amplicons derived by the specific primer binding is given according to the experiments run on an Applied Biosystems 7500 Real-Time PCR System

the ancient cattle Bos primigenius from Eurasia [20]. Current brucellosis programs strictly control cattle movements, but these programs have been only recently established, and B. abortus has likely been influenced by several centuries of introductions and disseminations of infected cattle throughout Italy. Thus, contemporary B. abortus diversity and distributions may reflect past mixing of cattle of different origins.

The newly developed Melt-MAMA assays specific to the three Italian clades and subclades allowed us to
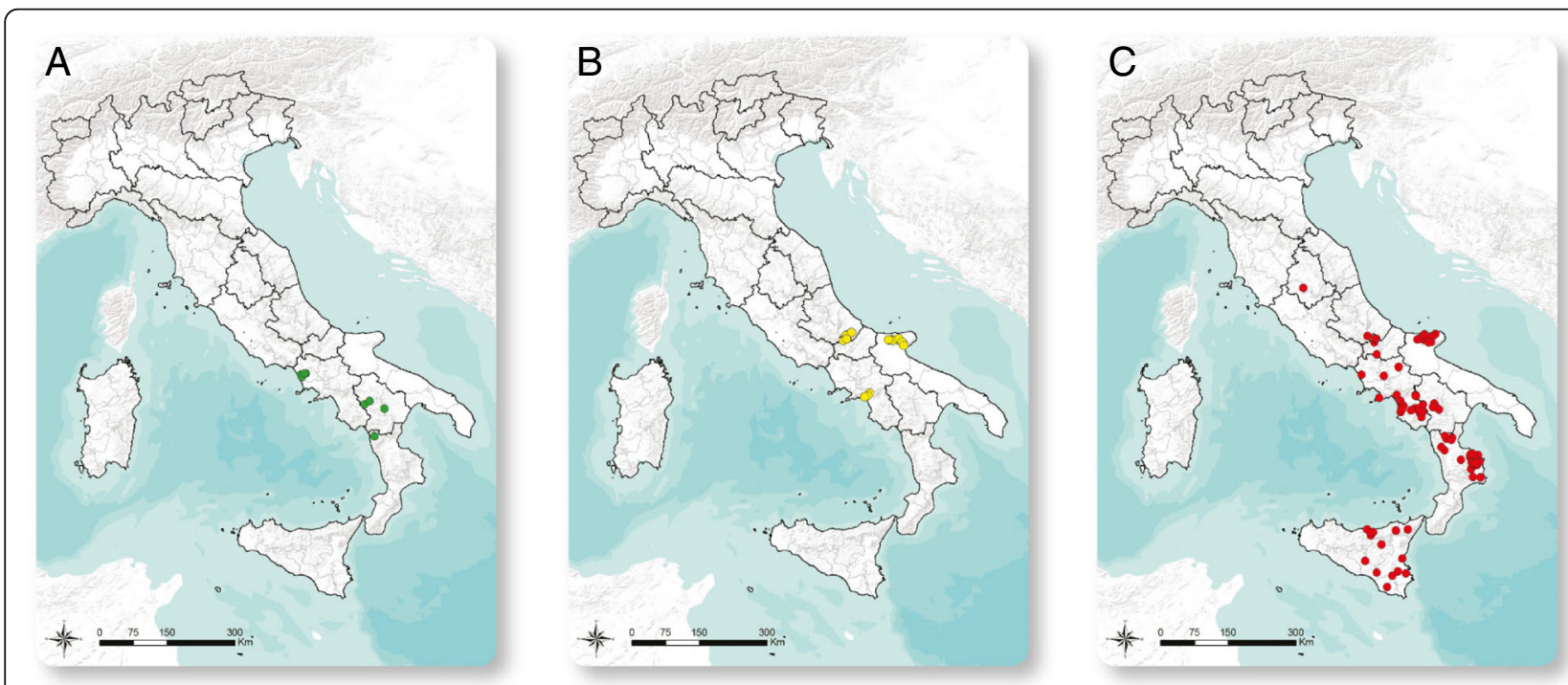

Fig. 2 Geographical mapping of the Italian isolates of Brucella abortus according to Melt-MAMA genotyping. GIS coordinates separated by groups are shown as follow: green for the West Italia group (a), yellow for the East Italia (b) and red for the Trans Italia (c) 
screen a large collection of isolates and quickly and inexpensively assign them to one of three genetic groups. Future testing of additional isolates using these six SNP assays during eradication programs will allow them to be typed more rapidly and confidently than biotyping, and could serve Italian diagnostic laboratories as a first line assay. Genotyping coupled with knowledge of herd movement through use of risk maps, spatial modeling, and Social Network Analysis (SNA) techniques should enhance the reliability of the Italian brucellosis eradication plan. Although a multiplex PCR approach has been developed recently [14], and the MLVA-16 has been shown to be robust and informative [21], these techniques remain cumbersome for data production and standardization. Perhaps a more reasonable approach would be to pair the SNP assays with a limited number of VNTR loci to achieve a higher resolution for molecular epidemiology purposes.

\section{Conclusion}

We recognize the capabilities of whole genome sequencing, but we are also aware that this technology is not yet accessible to all labs and requires skills that are not present in many diagnostic laboratories. Nonetheless, for some outbreak investigations, MLVA-16 or whole genome sequencing may be essential when complete epidemiological traceback is required. Ultimately, our study demonstrates the utility of WGS SNPs paired with extensive epidemiologic data for analyzing the distribution of $B$. abortus isolates throughout endemic regions.

\section{Methods}

Aims of the study

The study was conducted to genetically characterize Italian

B. abortus isolates from 261 animal cases in Southern Italy from 2011 to 2014. The overall goal was to trace the origin and the global connections of bovine brucellosis in Italy and to develop a rapid genotyping method for novel isolates.

\section{B. abortus isolates}

Large ruminants (cattle and water buffalo) and small ruminants (sheep and goat) testing positive positive for brucellosis in the serological tests carried out in the context of the national brucellosis eradication campaign were slaughtered. Isolation and characterization of Brucella spp. then occurred using selected tissues or body fluids. The preferred tissues for culture are lymphatic glands (i.e. mammary and genital lymph nodes, and spleen), uterus, and udder. Direct and enrichment Brucella cultures were carried out with these tissue samples following the OIE procedures. The suspected colonies were assigned to the species $B$. abortus and biovar designation (biovars $1-7,9)$ using PCR and traditional biochemical testing and serotyping [22]. All cultured isolates were stored in the Italian collection with associated epidemiological data. To achieve maximum diversity necessary for these types of projects, we followed the guidelines Pearson et al. [23] and used results from our VNTR study [17] to select 11 phylogenetically and geographically diverse $B$. abortus strains for whole genome sequencing (Table 2).

\section{Whole genome sequencing and SNP detection}

We sequenced isolate DNA on an Illumina MiSeq using $300 \mathrm{bp}$ paired-end reads and a $400 \mathrm{bp}$ insert size (GenBank PRJNA284953) [24]. SNPs were determined with NASP version 1.0.0 [25], using default filters to remove SNPs from duplicated regions, read coverage less than 10X, base call proportion less than $90 \%$, and loci not orthologous in all samples. NASP uses BWA [26] as the aligner and GATK [27] as the SNP caller. This analysis

Table 2 Epidemiological data for 11 Brucella abortus isolates that were whole genome sequenced. All samples were collected in 2011 and were molecularly identified as B. abortus

\begin{tabular}{lllll}
\hline Sample ID & Region & Province & Town & Host \\
\hline 1046 & Abruzzo & CH & Roccaspinalveti & cattle \\
5586 & Calabria & KR & Pallagorio & cattle \\
8486 & Campania & SA & Giffoni Valle Piana & cattle \\
9060 & Calabria & CS & Scala Coeli & cattle \\
$8979-3$ & Campania & CE & Cancello ed Arnone & water buffalo \\
11796 & Sicilia & ME & Tusa & cattle \\
12183 & Campania & SA & Corleto Monforte & cattle \\
$15074 / 1$ & Puglia & FG & San Marco in Lamis & cattle \\
$1365 / 1$ & Molise & Carovilli & cattle \\
3272 & Puglia & FG & Apricena & cattle \\
9261 & Calabria & CS & Papasidero & cattle \\
\hline
\end{tabular}


allowed us to compare these 11 genomes to 179 genomes of B. abortus from GenBank, accessed via PATRIC [28], that have been examined as part of a global analysis of $B$. abortus (JTF, unpubl. data). Phylogenetic trees were constructed using maximum parsimony in PAUP* 4.0b [29]. Branch support was assessed with 1000 bootstrap replicates and a consistency index was generated to assess the level of homoplasy.

\section{Melt-MAMA PCR assays}

We designed SNP-specific assays, detailed in Table 1, that targeted six specific Italian clades in the phylogenetic tree (Fig. 1). Downstream real-time PCR analyses using Melt-MAMA were performed on 261 B. abortus isolates isolated in Italy from the endemic territories during the period 2011-2014 (Supplementary material). Briefly, Melt-MAMA allows sensitive genotyping assays to be developed that distinguish samples containing a single nucleotide difference, which can be robust determinants of specific lineages in clonal bacteria [30]. The assays satisfied the following five conditions as previously described [31], including: (i) Two 3' forward primers containing sequences complementary to the allelic sequence for each SNP; (ii) a common reverse primer; (iii) an additional mismatch in the forward primer in anti-penultimate and penultimate position, alternately; (iv) a $5^{\prime}$ GC-clamp for one of the forward primers; (v) small sized amplicon (60-120 bp). Relative primer concentrations were tested in ratios of 1:1, 4:1, and 1:4 during optimization of the PCR reaction conditions. Assays were considered valid when they gave consistently different melt profiles for samples containing SNPs for known ancestral versus derived alleles.

\section{Additional file}

Additional file 1: Table S1. Information regarding $B$. abortus analyzed in this study. Additional information regarding strains studied with clade assignation according to the real time PCR assays. (XLSX $30 \mathrm{~kb}$ )

\section{Abbreviations}

BSL: Biosafety level 3 laboratory; Melt-MAMA: Melt analysis using mismatch amplification mutation assays; MLVA: Multi Locus VNTRs Analysis; PCR: Polymerase chain reaction; SNPs: Single nucleotide polymorphisms; VNTR: Variable number tandem repeat

\section{Acknowledgments}

We thank Istituti Zooprofilattici Sperimentali (IIZZSS) staff for technical support. We are grateful to Paola Di Giuseppe for providing assistance on figure graphics.

\section{Funding}

The work was supported by the Italian Ministry of Health with the Ricerca Corrente 2012 funds, project IZSAM02/12RC. Funding to JTF from the U.S. Department of Homeland Security (DHS) also supported this work. Use of product or trade names does not constitute endorsement by the U.S. Government.

\section{Availability of data and materials}

The genomes are available at GenBank under the project PRJNA284953.

Phylogenetic data is deposited in the TreeBase database (study 20401).

\section{Authors' contributions}

GG and JTF designed the study and drafted the final manuscript, EDG, FDM, CC and PC contributed in planning the project and critically reviewed the manuscript, IP, AA, LS, KZ, GDD and MA performed the WGS, Melt-MAMA and conventional tests for typing the Brucella isolates, GG, JTF and KPD conducted the bioinformatics analyses. All authors read and approved the final manuscript.

\section{Competing interests}

The authors declare that they have no competing interests.

\section{Consent for publication}

Not applicable.

\section{Ethics approval and consent to participate}

This study is a retrospective molecular investigation of the Brucella collection from the National and OIE Reference Laboratory Istituto Zooprofilattico Sperimentale dell'Abruzzo e del Molise. No human or animal data were used therefore informed consent was not required.

\section{Author details}

${ }^{1}$ National and OIE Reference Laboratory for Brucellosis, Istituto Zooprofilattico Sperimentale dell'Abruzzo e del Molise "G. Caporale", Teramo, Italy.

${ }^{2}$ Department of Molecular, Cellular, and Biomedical Sciences, University of New Hampshire, Durham, NH, USA.

Received: 15 June 2016 Accepted: 24 January 2017

Published online: 02 February 2017

\section{References}

1. EFSA (European Food Safety Authority), ECDC (European Centre forDisease Prevention and Control). The European Union summary report on trends and sources of zoonoses, zoonotic agents and food-borne outbreaks in 2014. EFSA J. 2015;13(12):4329.

2. Alton GG, Forsyth JRL. Brucella. In: Galveston SB, editor. Medical Microbiology. Fourthth ed. Texas: University of Texas Medical Branch; 1996. p. 137-46.

3. Bang B. The etiology of epizootic abortion. J Comp Pathol Ther. 1897;10: 125IN122-149.

4. Meyer KF, Shaw EB. A comparison of the morphologic, cultural and biochemical characteristics of B. abortus and B. melitensis* studies on the genus Brucella nov. gen. I. J Infect Dis. 1920;27(3):173-84.

5. Godfroid J, Cloeckaert A, Liautard J-P, Kohler S, Fretin D, Walravens K, Garin-Bastuji B, Letesson J-J. From the discovery of the Malta fever's agent to the discovery of a marine mammal reservoir, brucellosis has continuously been a re-emerging zoonosis. Vet Res. 2005;36:313-26.

6. Seleem MN, Boyle SM, Sriranganathan N. Brucellosis: a re-emerging zoonosis. Vet Microbiol. 2010;140(3-4):392-8.

7. Young EJ, Corbel MJ. Brucellosis: Clinical and Laboratory Aspects. Boca Raton: CRC press; 1989. ISBN 0-8493-6661-5.

8. Italian Ministry of Health. Decreto n. 651 del 27 agosto 1994. Regolamento concernente il piano nazionale per la eradicazione della brucellosi negli allevamenti bovini. In.: Gazzetta Ufficiale Serie Generale n. 277 del 26 novembre 1994; 1994

9. Graziani C, Mancini FR, Adone R, Marianelli C, Pasquali P, Rizzo C, Bella A, De Massis F, Danzetta ML, Calistri P, et al. La brucellosi in Italia dal 1998 al 2011, Roma: Istituto Superiore di Sanità (Rapporti ISTISAN 13/45). 2013. p. 75.

10. Calistri P, lannetti S, Atzeni M, Di Bella C, Schembri P, Giovannini A. Risk factors for the persistence of bovine brucellosis in Sicily from 2008 to 2010. Prev Vet Med. 2012;110(3):329-34.

11. Foster JT, Beckstrom-Sternberg SM, Pearson T, Beckstrom-Sternberg JS, Chain PS, Roberto FF, Hnath J, Brettin T, Keim P. Whole-genome-based phylogeny and divergence of the genus Brucella. J Bacteriol. 2009;191(8):2864-70.

12. Garin-Bastuji B, Mick V, Le Carrou G, Allix S, Perrett LL, Dawson CE, Groussaud P, Stubberfield EJ, Koylass M, Whatmore AM. Examination of taxonomic uncertainties surrounding Brucella abortus biovar 7 using phenotypic and molecular approaches. Appl Environ Microbiol. 2013;AEM. 03755-03713. 
13. Ferreira AC, Chambel L, Tenreiro T, Cardoso R, Flor L, Dias IT, Pacheco T, Garin-Bastuji B, Le Flèche P, Vergnaud G, et al. MLVA16 typing of Portuguese human and animal Brucella melitensis and Brucella abortus isolates. PLoS One. 2012;7(8):e42514.

14. Garofolo G, Ancora M, Di Giannatale E. MLVA-16 loci panel on Brucella spp. using multiplex PCR and multicolor capillary electrophoresis. J Microbiol Methods. 2013;92(2):103-7.

15. Allen A, Breadon E, Byrne A, Mallon T, Skuce R, Groussaud P, Dainty A, Graham J, Jones K, Pollock L. Molecular epidemiology of Brucella abortus in Northern Ireland-1991 to 2012. PLoS One. 2015;10(9):e0136721.

16. Her M, Kang SI, Cho DH, Cho YS, Hwang IY, Heo YR, Jung SC, Yoo HS. Application and evaluation of the MLVA typing assay for the Brucella abortus strains isolated in Korea. BMC Microbiol. 2009;9:230.

17. Garofolo G, Di Giannatale E, De Massis F, Zilli K, Ancora M, Camma C, Calistri P, Foster JT. Investigating genetic diversity of Brucella abortus and Brucella melitensis in Italy with MLVA-16. Infect Genet Evol. 2013;19:59-70.

18. Decker JE, McKay SD, Rolf MM, Kim J, Molina Alcalá A, Sonstegard TS, Hanotte O, Götherström A, Seabury CM, Praharani L, et al. Worldwide patterns of ancestry, divergence, and admixture in domesticated cattle. PLoS Genet. 2014;10(3):e1004254.

19. Groeneveld LF, Lenstra JA, Eding H, Toro MA, Scherf B, Pilling D, Negrini $R$, Finlay EK, Jianlin H, Groeneveld E, et al. Genetic diversity in farm animals-a review. Anim Genet. 2010;41(s1):6-31.

20. Moioli B, Napolitano F, Catillo G. Genetic diversity between Piedmontese, Maremmana, and Podolica cattle breeds. J Hered. 2004;95(3):250-6.

21. Le Fleche P, Jacques I, Grayon M, Al Dahouk S, Bouchon P, Denoeud F, Nockler K, Neubauer H, Guilloteau LA, Vergnaud G. Evaluation and selection of tandem repeat loci for a Brucella MLVA typing assay. BMC Microbiol. 2006;6(1):9.

22. OIE Office International des Epizooties, World Organization for Animal Health: Chapter 2.1.4. Brucellosis (Brucella abortus, B. melitesis, and B. suis) (Infection with B. abortus, B. melitesis and B. suis). Manual of diagnostic tests and vaccines for terrestrial animals 2016 (Available at: http://www.oie. int/fileadmin/Home/eng/Health_standards/tahm/2.01.04_BRUCELLOSIS.pdf ). Accesed 4 May 2016

23. Pearson T, Okinaka RT, Foster JT, Keim P. Phylogenetic understanding of clonal populations in an era of whole genome sequencing. Infect Genet Evol. 2009;9(5):1010-9.

24. Garofolo G, Foster JT, Drees K, Zilli K, Platone I, Ancora M, CammÃ C, De Massis F, Calistri P, Di Giannatale E. Genome sequences of 11 Brucella abortus isolates from persistently infected Italian regions. GenomeA. 2015;3(6):e01402-01415.

25. Sahl JW, Lemmer D, Travis J, Schupp J, Gillece J, Aziz M, Driebe E, Drees K, Hicks N, Williamson C, et al. The Northern Arizona SNP Pipeline (NASP): accurate, flexible, and rapid identification of SNPs in WGS datasets. bioRxiv. 2016 http//biorxiv.org/content/biorxiv/early/2016/01/25/037267.full.pdf. Accessed 4 May 2016

26. Li H, Durbin R. Fast and accurate short read alignment with Burrows-Wheeler transform. Bioinformatics. 2009:25(14):1754-60.

27. McKenna A, Hanna M, Banks E, Sivachenko A, Cibulskis K, Kernytsky A, Garimella K, Altshuler D, Gabriel S, Daly M, et al. The Genome Analysis Toolkit: a MapReduce framework for analyzing next-generation DNA sequencing data. Genome Res. 2010;20(9):1297-303.

28. Wattam AR, Abraham D, Dalay O, Disz TL, Driscoll T, Gabbard JL, Gillespie JJ, Gough R, Hix D, Kenyon R, et al. PATRIC, the bacterial bioinformatics database and analysis resource. Nucleic Acids Res. 2014;42(Database issue):D581-91.

29. Swofford DL: PAUP*: phylogenetic analysis using parsimony, version 4.0 b10. 2003.

30. Keim P, Van Ert MN, Pearson T, Vogler AJ, Huynh LY, Wagner DM. Anthrax molecular epidemiology and forensics: using the appropriate marker for different evolutionary scales. Infect Genet Evol. 2004;4(3):205-13.

31. Birdsell DN, Pearson T, Price EP, Hornstra HM, Nera RD, Stone N, Gruendike J, Kaufman EL, Pettus AH, Hurbon AN. Melt analysis of mismatch amplification mutation assays (Melt-MAMA): a functional study of a cost-effective SNP genotyping assay in bacterial models. PLoS One. 2012;7(3):e32866. 32810. 31371/journal.pone.0032866.

\section{Submit your next manuscript to BioMed Central and we will help you at every step:}

- We accept pre-submission inquiries

- Our selector tool helps you to find the most relevant journal

- We provide round the clock customer support

- Convenient online submission

- Thorough peer review

- Inclusion in PubMed and all major indexing services

- Maximum visibility for your research

Submit your manuscript at www.biomedcentral.com/submit
Biomed Central 